\title{
Ergothioneine prevents endothelial dysfunction induced by mercury chloride
}

\author{
GÖKSEL GÖKÇE, MEHMET ZUHURI ARUN and ELIF ERTUNA \\ Department of Clinical Pharmacy, Faculty of Pharmacy, Ege University, Izmir 35040, Turkey
}

Received November 28, 2017; Accepted February 22, 2018

DOI: $10.3892 /$ etm.2018.6079

\begin{abstract}
Exposure to mercury has detrimental effects on the cardiovascular system, particularly the vascular endothelium. The present study aimed to investigate the effects of ergothioneine (EGT) on endothelial dysfunction induced by low-dose mercury chloride $\left(\mathrm{HgCl}_{2}\right)$. Agonist-induced contractions and relaxations were evaluated in isolated aortic rings from 3-month-old male Wistar rats treated by intra-muscular injection to caudal hind leg muscle with $\mathrm{HgCl}_{2}$ (first dose, $4.6 \mu \mathrm{g} / \mathrm{kg}$; subsequent doses, $0.07 \mu \mathrm{g} / \mathrm{kg} /$ day for 15 days) and optionally with EGT ( $2 \mu \mathrm{g} / \mathrm{kg}$ for 30 days). Reactive oxygen species (ROS) in aortic rings were measured by means of lucigenin- and luminol-enhanced chemiluminescence. The protein level of endothelial nitric oxide synthase was evaluated by ELISA. Blood glutathione (GSH) and catalase levels, lipid peroxidation and total nitrite were measured spectrophotometrically. The results indicated that low-dose $\mathrm{HgCl}_{2}$ administration impaired acetylcholine ( $\mathrm{ACh}$ )-induced relaxation and potentiated phenylephrine- and serotonin-induced contractions in rat aortas. In addition, $\mathrm{HgCl}_{2}$ significantly increased the levels of ROS in the aortic tissue. EGT prevented the loss of ACh-induced relaxations and the increase in contractile responses. These effects were accompanied by a significant decrease in ROS levels. EGT also improved the ratio of reduced GSH to oxidized GSH and catalase levels with a concomitant decrease in lipid peroxidation. In conclusion, to the best of our knowledge, the present study was the first to report that EGT prevents endothelial dysfunction induced by low-dose $\mathrm{HgCl}_{2}$ administration. EGT may serve as a therapeutic tool to reduce mercury-associated cardiovascular complications via improving the antioxidant status.
\end{abstract}

\section{Introduction}

Chronic exposure to heavy metals poses a serious health threat. Among these, mercury, considered by the World

Correspondence to: Dr Göksel Gökçe, Department of Clinical Pharmacy, Faculty of Pharmacy, Ege University, Bornova, Izmir 35040, Turkey

E-mail: goksel.gokce@ege.edu.tr

Key words: mercury toxicity, ergothioneine, endothelial dysfunction
Health Organization as one of the top ten chemicals of major public health concern (1), has been used for numerous years for a variety of purposes (2). Exposure mostly occurs through consumption of fish and fishery products contaminated with organic mercury, inhalation of mercury vapour from dental amalgams and from vaccines containing thiomersal (3). Fish and sea mammals are increasingly becoming a source of mercury toxicity (4). For a long time, mercury was principally thought to affect central nervous system, thus leading to degenerative diseases (5). However, as extensively reviewed by Fernandes Azevedo et al (6), mercury also produces profound cardiovascular toxicity. Mercury has been demonstrated to induce endothelial dysfunction in experimental models using low doses of mercury (7-11), attaining the blood mercury concentration just above the safe level recommended by the Environmental Protection Agency (12). In these studies, reduction of nitric oxide (NO) bioavailability and increased oxidative stress consistent with high levels of reactive oxygen species (ROS) were noted as major causes of endothelial dysfunction observed in low-dose mercury toxicity. In the light of the above, antioxidants may have therapeutic potential in the prevention of mercury-induced endothelial dysfunction. This notion is further supported by a study by Rizetti et al (9), which demonstrated that apocynin improves endothelial dysfunction in aortas of rats exposed to nanomolar concentrations of mercury.

Ergothioneine (EGT) is an ubiquitous histidine derivative occurring in higher-order plants and animals (13). In humans, EGT accumulates in cells and tissues, which are frequently exposed to oxidative stress, including the liver, bone marrow, lens of the eye, seminal fluid and blood (14-16). Organic cation transporter, novel, type 1 , encoded by the gene solute carrier family 22, member 4, mediates the cellular uptake of EGT (17). In contrast to the major tissue antioxidant glutathione (GSH), EGT is resistant to autoxidation and does not form disulphides under physiological conditions $(18,19)$. Several lines of in vitro evidence suggest that EGT is a potent scavenger of ROS (20-26). Furthermore, a previous study by our group reported for the first time that EGT produces relaxation in isolated rat aortas by inactivating superoxide anions (27). This result and those of further studies, which indicate a potential role for EGT in the protection of endothelium (28-30), prompted us to examine its effects on mercury-induced endothelial dysfunction. The present study was performed to evaluate the effects of EGT on vascular reactivity in aortic rings from rats, 
which were treated with nanomolar concentrations of mercury chloride.

\section{Materials and methods}

Animals. Male Wistar rats (Lemali Ltd., Ankara, Turkey; weight, 150-175 g; age, 3 months; $n=18$ ) were used in the present study. The protocol for the animal experiment was approved by the Ethics Committee of Dokuz Eylül University (Izmir, Turkey; approval no. B.30.2/DEU/0.01/9402). The rats were provided pelleted food and water ad libitum and were maintained under constant temperature $\left(22 \pm 2^{\circ} \mathrm{C}\right)$ and at a relative humidity level of $50 \%$ with a 12 -h light/dark cycle. Animals were divided into three groups ( $n=6$ in each) and treated for 30 days as follows: i) Control [0.9\% NaCl, $0.5 \mathrm{ml}$ administered by intramuscular (IM) injection]; ii) Mercury chloride $\left(\mathrm{HgCl}_{2}\right)$ (first dose, $4.6 \mu \mathrm{g} / \mathrm{kg}$; maintenance doses, $0.07 \mu \mathrm{g} / \mathrm{kg} / \mathrm{day}$, IM, to make up for daily loss) (10); and iii) $\mathrm{HgCl}_{2}+\mathrm{EGT}(2 \mathrm{mg} / \mathrm{kg}$, IM).

Reagents. EGT, potassium chloride $(\mathrm{KCl})$, acetylcholine hydrochloride $(\mathrm{ACh})$, phenylephrine hydrochloride (PE), serotonin hydrochloride (5-HT) and $\mathrm{HgCl}_{2}$ were obtained from Sigma-Aldrich (Merck KGaA, Darmstadt, Germany). All drugs were dissolved in saline $(0.9 \% \mathrm{NaCl})$.

Preparation of samples. Blood samples were collected by cardiac puncture under anesthesia with ketamine $(100 \mathrm{mg} / \mathrm{kg}) /$ xylazine $(10 \mathrm{mg} / \mathrm{kg})$ administered by intraperitoneal injection; the rats were then sacrificed by decapitation. The thoracic aorta was removed, cleaned of fat and loose connective tissue, and cut into $2 \mathrm{~mm}$-thick transverse rings. Aortic rings were suspended between two stainless hooks in 10-ml organ baths filled with Krebs solution gassed with $95 \% \mathrm{O}_{2}-5 \% \mathrm{CO}_{2}$ at $37^{\circ} \mathrm{C}$. The composition of $\mathrm{Krebs}$ solution was (in mM): $\mathrm{NaCl}, 118 ; \mathrm{KCl}, 4.7 ; \mathrm{CaCl}_{2} \times 2 \mathrm{H}_{2} \mathrm{O}, 2.5 ; \mathrm{KH}_{2} \mathrm{PO}_{4}$, 1.20; $\mathrm{MgSO}_{4}$ x 7 $\mathrm{H}_{2} \mathrm{O}, 1.17$; glucose, 11.1; $\mathrm{NaHCO}_{3}, 25$. A resting tension of $2 \mathrm{~g}$ was applied to the aortic rings, which were then allowed to equilibrate for $45 \mathrm{~min}$ prior to further experimentation. In this period, tissues were washed out with Krebs solution every $15 \mathrm{~min}$. Isometrical changes in tension were processed with MLT0201/RAD force transducers (AD Instruments, Inc., Colorado Springs, CO, USA) and recorded on LabChart Pro (version 7.1; AD Instruments, Inc.).

Experimental protocol for vascular reactivity studies. Concentration-response curves to ACh $\left(10^{-9}-10^{-4} \mathrm{M}\right)$ were recorded in aortic rings previously contracted with $\mathrm{PE}\left(10^{-6} \mathrm{M}\right)$. After a washout period of $45 \mathrm{~min}$, concentration-response curves to PE $\left(10^{-9}-10^{-4} \mathrm{M}\right)$ and to 5 -HT $\left(10^{-9}-10^{-4.5} \mathrm{M}\right)$ were recorded, respectively.

Detection of ROS. Levels of ROS were determined according to the method described by Wang et al (31), with slight modifications. After a 30-min stabilization period in Krebs solution maintained at $37^{\circ} \mathrm{C}$ and gassed with $95 \% \mathrm{O}_{2}-5 \% \mathrm{CO}_{2}$, aortic rings were transferred to solid white 96-well plates containing $200 \mu 1$ HEPES-buffered Krebs solution (pH 7.4). Following addition of lucigenin or luminol (final concentration of either, $5 \mu \mathrm{mol} / \mathrm{l})$, ROS were quantified using a multi-plate reader
(Victor III-1420; Perkin Elmer, Inc., Waltham, MA, USA). Counts were obtained at 10 -second intervals and corrected for wet tissue weight. Results were expressed as the area under curve (AUC) for a counting period of $10 \mathrm{~min}$ [AUC of relative light units/mg wet tissue].

Tissue homogenization. Aortic tissue was homogenized on ice in PBS (pH 7.4) using a sonicator (Bandelin Sonopuls, UW 2070; Bandelin, Berlin, Germany). Homogenate was centrifuged at $10,000 \mathrm{x}$ g for $20 \mathrm{~min}$ at $4^{\circ} \mathrm{C}$. The supernatant was aliquoted and stored at $-80^{\circ} \mathrm{C}$ for further evaluation. The protein content was determined by the method of Lowry et al (32).

Determination of total nitrite. Nitrite levels were determined after conversion of nitrate to nitrite by nitrate dehydrogenase (33). Aortic supernatant was mixed with an equal volume of Griess reagent (sulfanilamide 1\% w/v; naphtylethylenediamine dihydrochloride, $0.1 \% \mathrm{w} / \mathrm{v}$; and orthophosphoric acid, $25 \% \mathrm{v} / \mathrm{v}$ ). Following incubation at $37^{\circ} \mathrm{C}$ for $10 \mathrm{~min}$, the absorbance was read at $540 \mathrm{~nm}$. Total nitrite levels were determined from a standard curve with increasing concentrations of sodium nitrite and normalized to the protein content of the aortic sample.

Determination of endothelial NO synthase (eNOS). Protein levels of eNOS were determined in aortic supernatants by using an ELISA kit (cat. no. SEA868Ra; Wuhan USCN Business Co., Ltd., Wuhan, China) according to the manufacturer's protocols.

Measurement of oxidative stress markers. The levels of GSH (reduced form) and the ratio of GSH to oxidized glutathione (GSSG) in blood samples were determined using the Bioxytech ${ }^{\circledR}$ GSH/GSSG-412 assay (cat. no. 21040; Oxis International, Inc.; GT Biopharma, Inc., Washington, DC, USA) according to the manufacturer's protocols. The formation of malondialdehyde (MDA) and catalase activity in blood samples were determined using commercially available assay kits [Bioxytech ${ }^{\circledR}$ MDA-586 (cat. no. 21044) and Catalase-520 assay (cat. no. 21042), respectively; Oxis International, Inc.; GT Biopharma, Inc.] according to the manufacturer's protocols.

Statistical analysis. All values are expressed as the mean \pm standard error of the mean. Relaxation responses to $\mathrm{ACh}$ are expressed as percentage (\%) relaxation of the PE-induced tone. Contractile responses to PE and 5-HT are expressed as percentage (\%) of the $\mathrm{KCl}$-induced tone. Analysis of variance followed by Tukey's multiple comparisons test was performed using GraphPad Prism (Version 5.0 for Mac OS X; GraphPad Software, Inc., La Jolla, CA, USA). P<0.05 was considered to indicate a statistically significant difference.

\section{Results}

\section{Isometric tension recordings}

Relaxations. ACh induced concentration-dependent relaxations in PE-pre-contracted aortic rings from control and treated rats (Fig. 1A). Treatment with $\mathrm{HgCl}_{2}$ reduced $\mathrm{ACh}$-induced 
relaxations by up to $67.1 \%$ compared with the control group $(\mathrm{P}<0.001)$ and shifted the concentration-response curve to the right (Fig. 1A). EGT inhibited the impairment of ACh-induced relaxation observed in aortic rings from $\mathrm{HgCl}_{2}$-treated rats $\left(\mathrm{P}<0.001\right.$; Fig. 1) and significantly increased the $\mathrm{pD}_{2}$ values $\left(\mathrm{P}<0.01\right.$; Table I) compared with $\mathrm{HgCl}_{2}$-treated rats without EGT treatment.

Contractions. PE and 5-HT induced concentration-dependent contractions in aortic rings from control and treated rats (Fig. 1B and C). Treatment with $\mathrm{HgCl}_{2}$ significantly increased PE- and 5-HT-induced contractions compared with the control group $(\mathrm{P}<0.001$; Fig. 1B and $\mathrm{C})$ without affecting the sensitivity to either agent (Table I). Co-treatment with EGT prevented the increase in contractile response to $\mathrm{PE}$ and to 5-HT compared with $\mathrm{HgCl}_{2}$-treated rats without EGT treatment $(\mathrm{P}<0.001$; Fig. 1B and C).

Levels of $R O S$. Low-dose $\mathrm{HgCl}_{2}$ significantly increased the levels of ROS in the rat thoracic aortas (Fig. 2A and B). Lucigenin- and luminol-enhanced chemiluminescence in aortas from $\mathrm{HgCl}_{2}$-treated rats were $\sim 4.8$ and $\sim 5.2$ times higher than in those of control tissues, respectively (for either, $\mathrm{P}<0.001)$. EGT significantly reduced the ROS levels increased by $\mathrm{HgCl}_{2}$ treatment in $\mathrm{HgCl}_{2}+$ EGT-treated rats compared with $\mathrm{HgCl}_{2}$-treated rats without EGT treatment $(\mathrm{P}<0.001$; Fig. 2A and B).

Total nitrite and eNOS levels. Levels of total nitrite and eNOS remained unchanged among the experimental groups (Fig. 3A and B).

Antioxidant status. Fig. 4 summarizes the effects of EGT on the antioxidant status in the blood of rats. Low-dose $\mathrm{HgCl}_{2}$ caused a significant increase in oxidative stress and lipid peroxidation, and reduced catalase activity. When compared with the control group, GSH levels and the GSH/GSSG ratio were significantly lower in $\mathrm{HgCl}_{2}$-treated rats $(\mathrm{P}<0.001$; Fig. 4A and B). Similarly, catalase activity decreased by $53.3 \%$ in $\mathrm{HgCl}_{2}$-treated rats compared with the control group ( $\mathrm{P}<0.001$; Fig. 4C). In addition, lipid peroxidation, as indicated by increased plasma MDA levels, increased by $\sim 1.3$-fold in $\mathrm{HgCl}_{2}$-treated rats compared with the control group $(\mathrm{P}<0.001$; Fig. 4D). Co-treatment with EGT not only restored the antioxidant status, but also significantly reduced lipid peroxidation in $\mathrm{HgCl}_{2}+\mathrm{EGT}$-treated rats compared with $\mathrm{HgCl}_{2}$-treated rats without EGT treatment $(\mathrm{P}<0.001$; Fig. 4D).

\section{Discussion}

Overall health effects of chronic exposure to mercury are a matter of serious concern and cardiovascular consequences of mercury toxicity remain an important area of research. As comprehensively reviewed by Houston (4), exposure to mercury is an underestimated risk factor for hypertension, coronary heart disease, myocardial infarction, reduction in heart rate variability, increase in carotid intima-media thickness and carotid obstruction, generalized atherosclerosis, renal dysfunction and proteinuria, and an overall increase in total and cardiovascular mortality. Garcia Gomez et al (34)
Table I. Effects of EGT on the sensitivity to ACh, PE and 5-HT in aortas from $\mathrm{HgCl}_{2}$-treated rats.

\begin{tabular}{lccc}
\hline Parameter & Control & $\mathrm{HgCl}_{2}$ & $\mathrm{HgCl}_{2}+\mathrm{EGT}$ \\
\hline Ach & $6.55 \pm 0.06$ & $6.16 \pm 0.07^{\mathrm{a}}$ & $6.46 \pm 0.05^{\mathrm{b}}$ \\
PE & $6.54 \pm 0.07$ & $6.59 \pm 0.09$ & $6.58 \pm 0.05$ \\
5-HT & $6.57 \pm 0.08$ & $6.64 \pm 0.07$ & $6.62 \pm 0.05$ \\
\hline
\end{tabular}

${ }^{\mathrm{a}} \mathrm{P}<0.001$ vs. Control. ${ }^{\mathrm{b}} \mathrm{P}<0.001$ vs. $\mathrm{HgCl}_{2}$. Values are expressed as the mean \pm standard error of mean $(n=6)$. EGT, ergothioneine; ACh, acetylcholine; PE, phenylephrine hydrochloride; 5-HT, serotonin hydrochloride.

reported that the occurrence of hypertension, stroke and total cardiovascular mortality in mercury mine workers is increased by $2.78-, 1.17$ - and 1.51 -fold, respectively. It may simply be assumed that these consequences are most probably due to high levels of occupational or environmental exposure to mercury. However, evidence from animal models producing blood mercury levels similar to those of average human exposure suggest that low-dose mercury promotes endothelial dysfunction (8-11), a systemic pathological state of the endothelium, which is widely accepted as an early crucial event in cardiovascular diseases $(35,36)$. The present study provides preliminary evidence that EGT, a ubiquitous, water soluble, sulphur-containing derivative of the amino acid histidine, prevents low-dose $\mathrm{HgCl}_{2}$-induced endothelial dysfunction.

The present results may be summarized as follows: i) Low-dose $\mathrm{HgCl}_{2}$ decreases the maximum value and sensitivity of the relaxation response to $\mathrm{ACh}$ and increases the maximum value of contractile responses to 5-HT and PE, ii) $\mathrm{HgCl}_{2}$ increases the levels of ROS in the thoracic aorta, iii) $\mathrm{HgCl}_{2}$ causes significant reductions in GSH and catalase levels and decreases the GSH/GSSG ratio, while markedly increasing MDA formation compared with that in the control group, and iv) EGT reverses the abovementioned $\mathrm{HgCl}_{2}$-induced alterations in antioxidant status and vascular reactivity.

In the present study, chronic low-dose $\mathrm{HgCl}_{2}$ administration to rats caused a marked decline in the relaxation response to $\mathrm{ACh}$ in isolated thoracic aortas by up to $67.1 \%$ and significantly decreased the sensitivity, which is consistent with the results of Wiggers et al (10). The present results indicate that the $\mathrm{HgCl}_{2}$-associated reduction in relaxant responses and sensitivity to $\mathrm{ACh}$ were almost completely reversed by EGT treatment. In addition, EGT suppressed the significant increases in contractile responses to 5-HT and $\mathrm{PE}$ in $\mathrm{HgCl}_{2}$-treated rats. A previous study by our group demonstrated that pre-treatment with EGT did not affect the ACh-induced relaxation responses in endothelium-intact rat aortic rings (27). However, in parallel experiments employing a model of oxidative stress, which is based on inhibition of endogenous $\mathrm{Cu} / \mathrm{Zn}$ superoxide dismutase leading to the accumulation of superoxide anions, EGT recovered the impaired ACh relaxation (27). In addition, EGT elicited a concentration-dependent relaxation effect in aortic rings, 

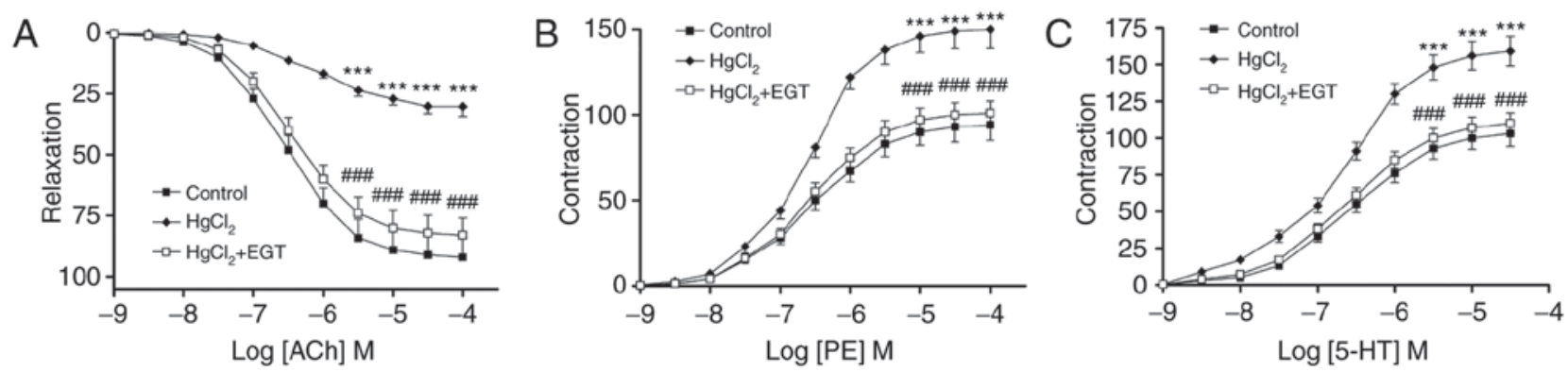

Figure 1. Effects of EGT on vascular reactivity in aortas from $\mathrm{HgCl}_{2}$-treated rats. (A) Relaxation responses to ACh. (B) Contractile responses to PE. (C) Contractile responses to 5-HT. Relaxation responses to $\mathrm{ACh}$ are expressed as the percentage relaxation of PE-induced tone. Contractile responses to PE and 5-HT are expressed as the percentage of $\mathrm{KCl}$-induced tone. Values are expressed as the mean \pm standard error of mean $(\mathrm{n}=6) .{ }^{* * *} \mathrm{P}<0.001 \mathrm{vs}$. Control.

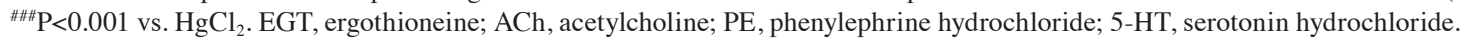
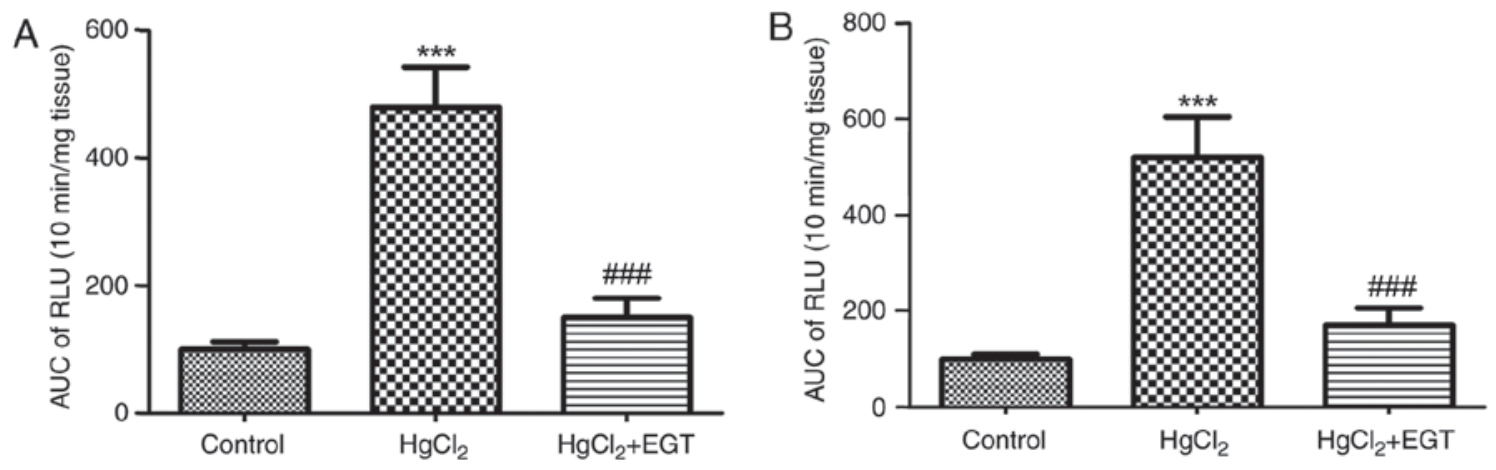

Figure 2. Effects of EGT on the levels of reactive oxygen species in aortas from $\mathrm{HgCl}_{2}$-treated rats. (A) Lucigenin-enhanced chemiluminescence. (B) Luminol-enhanced chemiluminescence. Values are expressed as the mean \pm standard error of mean $(\mathrm{n}=6) .{ }^{* * *} \mathrm{P}<0.001 \mathrm{vs}$. Control. ${ }^{\# \# \#} \mathrm{P}<0.001 \mathrm{vs}$. $\mathrm{HgCl}_{2}$. AUC, area under curve; RLU, relative light units; EGT, ergothioneine.
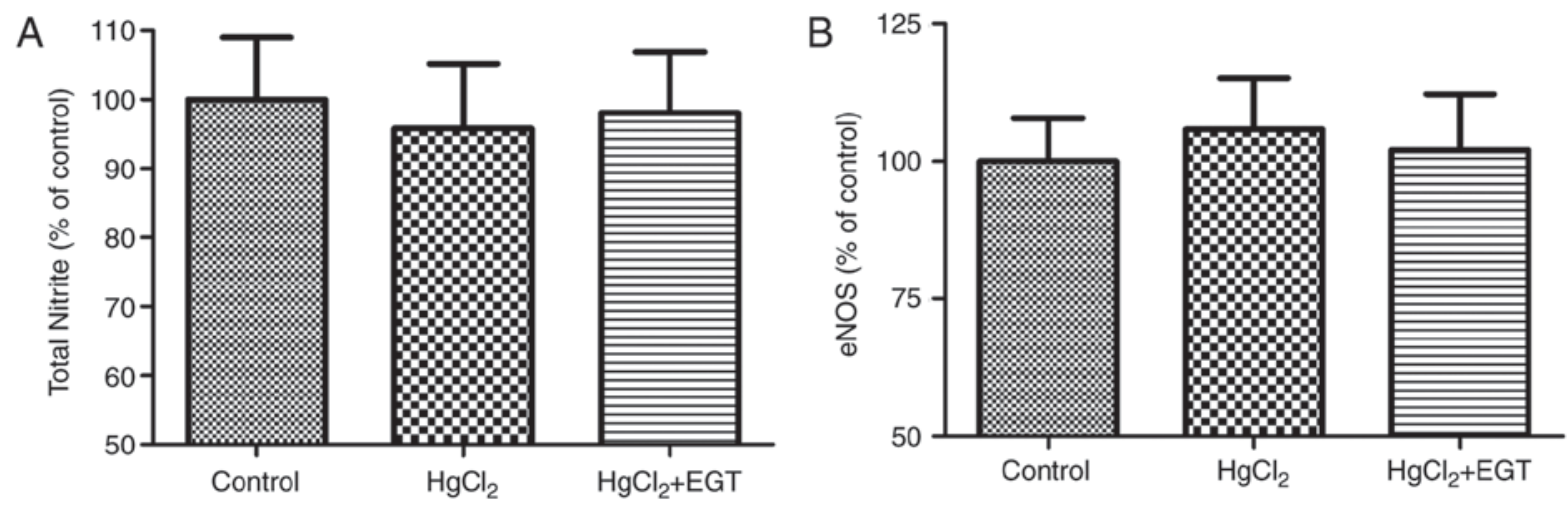

Figure 3. Effects of EGT on nitric oxide synthesis in aortas from $\mathrm{HgCl}_{2}$-treated rats. (A) Total nitrite levels. (B) eNOS levels. Values are expressed as the mean \pm standard error of mean $(n=6)$. EGT, ergothioneine; eNOS, endothelial nitric oxide synthase.

which was blunted by endothelial denudation or by inhibition of NOS (27). Taking the above results into consideration, the present study first investigated the possibility that EGT interferes with NO synthesis to increase Ach-induced relaxation. According to the present results, EGT does not appear to affect NO synthesis as reflected by similar total nitrite and eNOS levels among groups. This result gives rise to the question whether alterations in ROS levels and/or antioxidant status underlie the ameliorative effects of EGT on NO-dependent relaxations. Decreased bioavailability of NO due to increased superoxide anion production by NADPH oxidase is regarded as a crucial aspect of endothelial dysfunction observed in chronic exposure to low concentrations of mercury $(6,7,37)$. Superoxide anions not only participate in endothelial dysfunction, mainly owing to their rapid interaction with NO, but also produce direct biological effects and serve as a progenitor for numerous other ROS (38). Several studies revealed that EGT is a powerful scavenger of ROS and protects cells against a wide range of stressors $(20,26,27)$. Indeed, in the present study, high levels of ROS, including superoxide anions, observed in aortas from $\mathrm{HgCl}_{2}$-treated rats were significantly diminished by EGT treatment. As is known, NO rapidly reacts with 
A
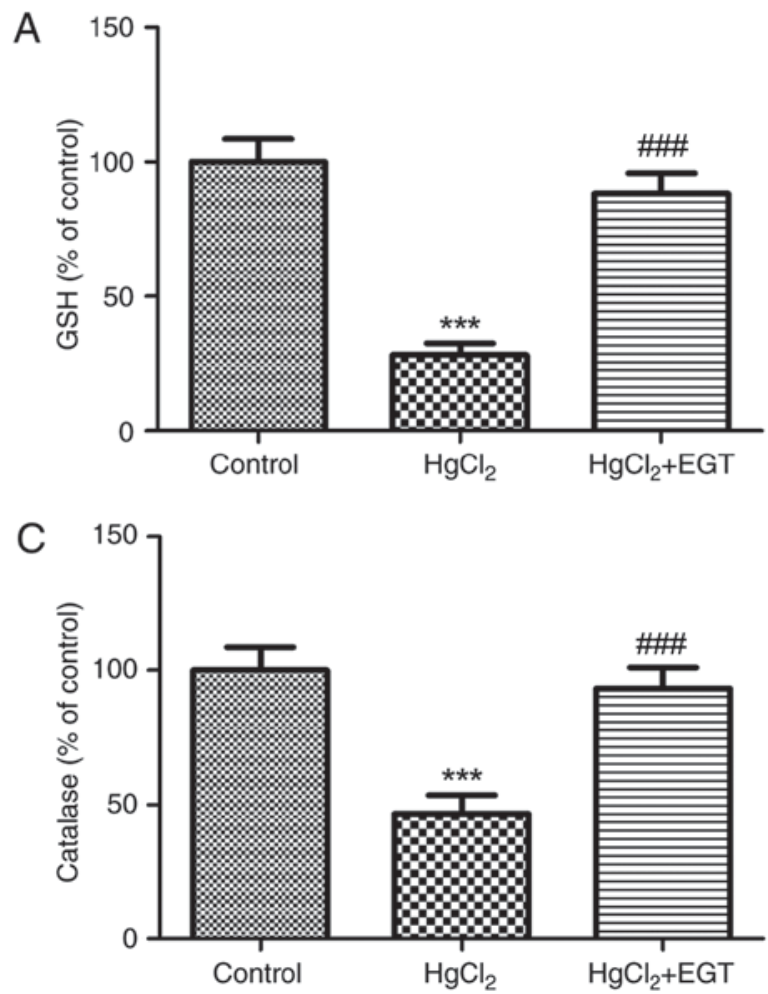

B
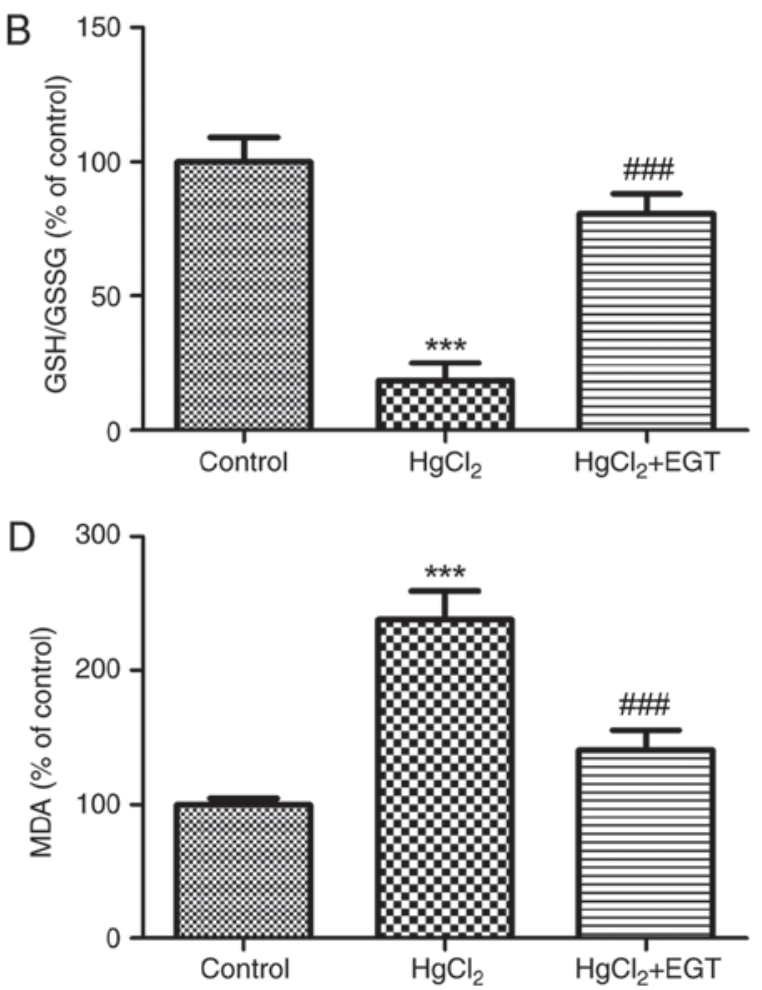

Figure 4. Effects of EGT on the blood antioxidant status from $\mathrm{HgCl}_{2}$-treated rats. (A) Levels of GSH, (B) GSH/GSSG ratio, (C) catalase levels and (D) MDA levels. Values are expressed as the mean \pm standard error of the mean $(\mathrm{n}=6) .{ }^{* * * *} \mathrm{P}<0.001$ vs. Control. ${ }^{\# \# t} \mathrm{P}<0.001 \mathrm{vs}$. $\mathrm{HgCl}_{2}$. GSH, reduced glutathione; GSSG, oxidized glutathione; EGT, ergothioneine; MDA, malondialdehyde.

superoxide anions to form peroxynitrite, leading to decreased NO bioavailability (39). Furthermore, peroxynitrite, the end product of this reaction, may also lead to eNOS uncoupling and cause vasoconstriction (39). Thus, it is concluded that the superoxide scavenging effects of EGT may lead to increased NO bioavailability and/or reduced eNOS uncoupling to restore impaired $\mathrm{ACh}$-induced relaxation without changing eNOS levels and/or NO production. In addition, EGT improved the antioxidant status by increasing GSH levels, the GSH/GSSG ratio and catalase activity, and by reducing lipid peroxidation. Apart from these results, the protective effects of EGT on vascular reactivity were also evident in contractile responses. EGT significantly reduced the increment in PE- and 5-HT-induced contractions. ROS, particularly superoxide anions, are regarded as endothelium-derived contracting factors, which have major roles in the regulation of the arterial tone (40). Furthermore, superoxide anions and hydrogen peroxide may be transformed into hydroxyl radicals, which was demonstrated to increase the synthesis of vasoconstrictor prostanoids (41). In this context, radical scavenging by and/or the antioxidant activity of EGT may account for the observed attenuation in contractile responses to PE and 5-HT.

In conclusion, the present study was the first to report that endothelial dysfunction induced by low doses of $\mathrm{HgCl}_{2}$ is prevented by EGT. It should be noted that EGT is acquired by humans through dietary means and accumulates in cells and tissues that are frequently exposed to oxidative stress (27). Taking into consideration that mercury-induced toxicity is often associated with poor prognosis due to limited treatment options, further studies evaluating the effects of EGT on the complications of mercury exposure may provide new insight for therapeutic intervention.

\section{Acknowledgements}

Not applicable.

\section{Funding}

This study was supported by the Scientific Research Fund of Ege University, Izmir, Turkey (grant no. 09-ECZ-024).

\section{Availability of data and materials}

The analyzed data sets generated during the study are available from the corresponding author on reasonable request.

\section{Authors' contributions}

GG conceived and designed the experiments. GG and MZA performed the experiments. GG, MZA and EE analyzed the results and wrote the paper. All authors have read and approved the final manuscript.

\section{Ethical approval and consent to participate}

The protocol for the animal experiment was approved by the Ethics Committee of Dokuz Eylül University (Izmir, Turkey; approval no. B.30.2/DEU/0.01/9402). 


\section{Consent for publication}

Not applicable.

\section{Competing interests}

The authors declare that they have no competing interests.

\section{References}

1. World Health Organization: Mercury and health. Fact sheet, 2016. http://www.who.int/mediacentre/factsheets/fs361/en/. Updated March 2017.

2. Salonen JT, Seppänen K, Nyyssönen K, Korpela H, Kauhanen J, Kantola M, Tuomilehto J, Esterbauer H, Tatzber F and Salonen R: Intake of mercury from fish, lipid peroxidation, and the risk of myocardial infarction and coronary, cardiovascular, and any death in eastern Finnish men. Circulation 91: 645-655, 1995.

3. Clarkson TW, Magos L and Myers GJ: The toxicology of mercury-current exposures and clinical manifestations. N Engl J Med 349: 1731-1737, 2003.

4. Houston MC: Role of mercury toxicity in hypertension, cardiovascular disease, and stroke. J Clin Hypertens (Greenwich) 13 621-627, 2011.

5. Mutter J, Naumann J, Sadaghiani C, Schneider R and Walach $H$ Alzheimer disease: Mercury as pathogenetic factor and apolipoprotein E as a moderator. Neuro Endocrinol Lett 25: 331-339, 2004.

6. Fernandes Azevedo B, Barros Furieri L, Peçanha FM, Wiggers GA, Frizera Vassallo P, Ronacher Simões M, Fiorim J, Rossi de Batista P, Fioresi M, Rossoni L, et al: Toxic effects of mercury on the cardiovascular and central nervous systems. J Biomed Biotechnol 2012: 949048, 2012.

7. Furieri LB, Galán M, Avendaño MS, García-Redondo AB Aguado A, Martínez S, Cachofeiro V, Bartolomé MV, Alonso MJ, Vassallo DV and Salaices M: Endothelial dysfunction of rat coronary arteries after exposure to low concentrations of mercury is dependent on reactive oxygen species. Br J Pharmacol 162: 1819-1831, 2011.

8. Pecanha FM, Wiggers GA, Briones AM, Perez-Giron JV, Miguel M, Garcia-Redondo AB, Vassallo DV, Alonso MJ and Salaices M: The role of cyclooxygenase (COX)-2 derived prostanoids on vasoconstrictor responses to phenylephrine is increased by exposure to low mercury concentration. J Physiol Pharmacol 61: 29-36, 2010.

9. Rizzetti DA, Torres JG, Escobar AG, Peçanha FM, Santos FW, Puntel RL, Alonso MJ, Briones AM, Salaices M, Vassallo DV and Wiggers GA: Apocynin prevents vascular effects caused by chronic exposure to low concentrations of mercury. PLoS One 8 : e55806, 2013.

10. Wiggers GA, Peçanha FM, Briones AM, Pérez-Girón JV, Miguel M, Vassallo DV, Cachofeiro V, Alonso MJ and Salaices M: Low mercury concentrations cause oxidative stress and endothelial dysfunction in conductance and resistance arteries. Am J Physiol Heart Circ Physiol 295: H1033-H1043, 2008.

11. Wiggers GA, Stefanon I, Padilha AS, Pecanha FM, Vassallo DV and Oliveira EM: Low nanomolar concentration of mercury chloride increases vascular reactivity to phenylephrine and local angiotensin production in rats. Comp Biochem Physiol C Toxicol Pharmacol 147: 252-260, 2008.

12. Rice DC: The US EPA reference dose for methylmercury: Sources of uncertainty. Environ Res 95: 406-413, 2004.

13. Cheah IK and Halliwell B: Ergothioneine; antioxidant potential, physiological function and role in disease. Biochim Biophys Acta 1822: 784-793, 2012.

14. Melville DB, Horner WH and Lubschez R: Tissue ergothioneine J Biol Chem 206: 221-228, 1954.

15. Shires TK, Brummel MC, Pulido JS and Stegink LD: Ergothioneine distribution in bovine and porcine ocular tissues. Comp Biochem Physiol C Pharmacol Toxicol Endocrinol 117: 117-120, 1997.

16. Shukla Y, Kulshrestha OP and Khuteta KP: Ergothioneine content in normal and senile human cataractous lenses. Indian J Med Res 73: 472-473, 1981

17. Gründemann D, Harlfinger S, Golz S, Geerts A, Lazar A, Berkels R, Jung N, Rubbert A and Schömig E: Discovery of the ergothioneine transporter. Proc Natl Acad Sci USA 102: $5256-5261,2005$.
18. Melville DB: Ergothioneine. Vitamin Horm 17: 155-204, 1959.

19. Paul BD and Snyder SH: The unusual amino acid L-ergothioneine is a physiologic cytoprotectant. Cell Death Differ 17: 1134-1140, 2010

20. Motohashi $\mathrm{N}$ and Mori I: The role of ergothioneine in the oxidation of reduced nicotinamide adenine dinucleotide by metmyoglobin or methemoglobin. Chem Pharm Bull (Tokyo) 31: 1702-1707, 1983

21. Reglinski J, Smith WE and Sturrock RD: Spin-echo 1H NMR detected response of ergothioneine to oxidative stress in the intact human erythrocyte. Magn Reson Med 6: 217-223, 1988.

22. Hartman PE: Ergothioneine as antioxidant. Methods Enzymol 186 310-318, 1990.

23. Akanmu D, Cecchini R, Aruoma OI and Halliwell B: The antioxidant action of ergothioneine. Arch Biochem Biophys 288: 10-16, 1991.

24. Aruoma OI, Whiteman M,England TG and Halliwell B: Antioxidant action of ergothioneine: Assessment of its ability to scavenge peroxynitrite. Biochem Biophys Res Commun 231: 389-391, 1997.

25. Mitsuyama $\mathrm{H}$ and May JM: Uptake and antioxidant effects of ergothioneine in human erythrocytes. Clin Sci (Lond) 97: 407-411, 1999

26. Franzoni F, Colognato R, Galetta F, Laurenza I, Barsotti M, D Stefano R, Bocchetti R, Regoli F, Carpi A, Balbarini A, et al: An in vitro study on the free radical scavenging capacity of ergothioneine: comparison with reduced glutathione, uric acid and trolox. Biomed Pharmacother 60: 453-457, 2006.

27. Gokce G and Arun MZ: Ergothioneine produces relaxation in isolated rat aorta by inactivating superoxide anion. Eur Rev Med Pharmacol Sci 18: 3339-3345, 2014.

28. Sit ASM, Ho EYW, Li RWS, et al: Ergothioneine shows protective effect on endothelial cells in oxidative stress. Faseb J 25: 630-633, 2011.

29. Martin KR: The bioactive agent ergothioneine, a key component of dietary mushrooms, inhibits monocyte binding to endothelial cells characteristic of early cardiovascular disease. J Med Food 13: 1340-1346, 2010.

30. Li RW, Yang C, Sit AS, Kwan YW, Lee SM, Hoi MP, Chan SW, Hausman M, Vanhoutte PM and Leung GP: Uptake and protective effects of ergothioneine in human endothelial cells. J Pharmacol Exp Ther 350: 691-700, 2014

31. Wang HD, Xu S, Johns DG, Du Y, Quinn MT, Cayatte AJ and Cohen RA: Role of NADPH oxidase in the vascular hypertrophic and oxidative stress response to angiotensin II in mice. Circ Res 88: 947-953, 2001

32. Lowry OH, Rosebrough NJ, Farr Al and Randall RJ: Protein measurement with the Folin phenol reagent. J Biol Chem 193: 265-275, 1951.

33. Majithiya JB, Paramar AN and Balaraman R: Pioglitazone, a PPARgamma agonist, restores endothelial function in aorta of streptozotocin-induced diabetic rats. Cardiovasc Res 66: 150-161, 2005.

34. Garcia Gomez M, Boffetta P, Caballero Klink JD, Espanol S and Gomez Quintana J: Cardiovascular mortality in mercury miners. Med Clin (Barc) 128: 766-771, 2007 (In Spanish).

35. Gokce N, Keaney JF Jr, Hunter LM, Watkins MT, Nedeljkovic ZS, Menzoian JO and Vita JA: Predictive value of noninvasively determined endothelial dysfunction for long-term cardiovascular events in patients with peripheral vascular disease. J Am Coll Cardiol 41: $1769-1775,2003$.

36. Widlansky ME, Gokce N, Keaney JF Jr and Vita JA: The clinical implications of endothelial dysfunction. J Am Coll Cardiol 42: 1149-1160, 2003.

37. Massaroni L, Rossoni LV, Amaral SM, Stefanon I, Oliveira EM and Vassallo DV: Haemodynamic and electrophysiological acute toxic effects of mercury in anaesthetized rats and in langendorff perfused rat hearts. Pharmacol Res 32: 27-36, 1995

38. Guzik TJ and Channon KM: Measurement of vascular reactive oxygen species production by chemiluminescence. Methods Mol Med 108: 73-89, 2005.

39. Pacher P, Beckman JS and Liaudet L: Nitric oxide and peroxynitrite in health and disease. Physiol Rev 87: 315-424, 2007.

40. Katusic ZS and Vanhoutte PM: Superoxide anion is an endothelium-derived contracting factor. Am J Physiol 257: H33-H37, 1989.

41. Vanhoutte PM: Endothelium-derived free radicals: For worse and for better. J Clin Invest 107: 23-25, 2001.

This work is licensed under a Creative Commons Attribution-NonCommercial-NoDerivatives 4.0 International (CC BY-NC-ND 4.0) License. 